\title{
ГРАЖДАНСКО-ПРАВОВАЯ ОТВЕТСТВЕННОСТЬ
}

Аннотаиия. Статья посвящена роли гражданско-правовой ответственности и этапам исторического становления в гражданском праве ответственности за вину. В ходе исследования были использованы исторический метод, сравнительно-правовой, могический. Особое внимание уделяется рассмотрению определений термина гражданско-правовая ответственность. Авторы приходят к выводу, что в настоящее время проблема понятия гражданскоправовой ответственности не решена Авторы делают вывод, что наблюдается усиление роли ответственности в соответствии с категорией вины и, как следствие этого, закрепление в нормативно-правовых актах новых случаев ответственности к имеющимся, а именно ответственность собственников, а также пользователей за вред, который был причинен принадлежащим вещам дикими животными, разрушающимися строениями.

Ключевые слова: гражданско-правовая ответственность, вина, состав правонарушения, принцип возмешения вреда.

\author{
E. B. Kazakova \\ Candidate of law, associate professor \\ Department of Private and Public Law \\ Penza State University, Penza, the Russian Federation \\ O. O. Potolokova \\ Master student \\ Penza State University, Penza, the Russian Federation
}

\section{CIVIL RESPONSIBILITY}

Abstract. Article is devoted to a role of civil responsibility and stages of historical formation in civil law of responsibility for fault. During the research have been used a historical method, comparative and legal, logical. Special attention is paid to consideration of definitions of the term civil responsibility. Authors conclude that now the problem of a concept of civil responsibility is not solved. Authors draw a conclusion that strengthening of a role of responsibility according to category of fault and, as a result of it, fixing in normative legal acts of new cases of responsibility to available is observed, namely responsibility of owners and also users for harm which was done to the belonging things by wild animals, the collapsing structures.

Key words: civil responsibility, wine, structure of offense, principle of indemnification.

Безусловно, необходимым условием стабильных отношений имущественного характера является законодательно установленная юридическая ответственность каждого субъекта гражданского оборота. В соответствии с Конституцией РФ, как известно, каждый имеет право на возмещение государством вреда, который был причинен незаконными действиями (ими же бездействием) органов государствен-

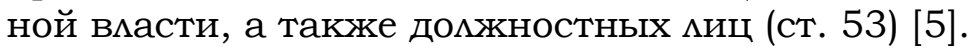


Бесспорно, принцип ответственности за вину в течение долгого времени утверждался гуманистической человеческой мыслью и со временем стал применяться в общественных правовых системах. Естественно, со становлением циви-

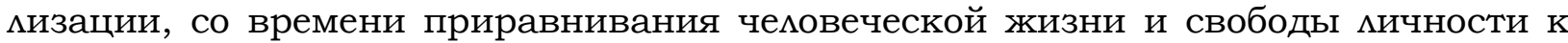
наиважнейшей ценности, ключевое место в правовой системе отводится принципу ответственности за вину, в соответствии с этим термин "вина" приобретает значимость.

Как известно, наличие в гражданском праве размичных категорий двух противоположностей - ответственности "за вину" и ответственности "без вины" все еще явцяется проблемой. Дмя того чтобы вывести универсальное определение понятия вина, необходимо проанализировать исторические периоды, на протяжении которых соотношение понятий ответственность "за вину" и ответственность «без вины" в гражданском праве изменялась [3].

По мнению ученых, первым этапом можно назвать древнейшее право, которое существовало в доклассический период истории Римского государства. Известно, что юридической ответственности, как правимо, в тот период еще не существовало, однако ее место занимала месть потерпевшего. Таким образом, использовалось понятие о вине, как о субъективном отношении правонарушителя к своему поведению, которое привело к неблагоприятным имущественным последствиям [7].

Известно, что субъективное отношение правонарушителя к его поведению и наступившим последствиям никаким образом не учитывалось, следовательно, дмя него такая ответственность фактически являлась "объективной". Безусловно, субъективное отношение потерпевшего к возникшим у него убыткам и к причи-

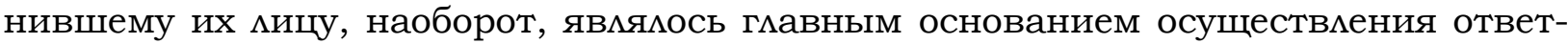
ственности мести. Следовательно, в связи с тем, что существовала неразвитость права, отсутствовало государственное правосудие, и все это вело к тому, что месть являлась одновременно и в качестве последствия всякого правонарушения и условия наступления данного последствия.

Не подвергается сомнению, что назначение ответственности-мести за правонарушение являлось наказанием, размер данного нарушения мог быть опредемен самим потерпевшим, а затем законами, в которых в письменной форме была закреплена возможность мести. В частности, Законы XII таблиц давали возможность преобразовывать несостоятельного должника в раба кредитора, а в ситуации, если задолжал нескольким Аюдям, на части разрубить в соответствии с размером домга [4].

Иначе говоря, осознание нежелательности дмя общества ответственностимести, не только не восстанавцивавшей положение потерпевшего, но и удваивавшей ущерб, который несло общество в целом, приводимо к принятию государственных мер, которые были направмены на ее ограничение.

В самом деме, в противовес предыдущему праву, была поставлена ответственность, которая подчинялась субъективным условиям: а именно умыслу (dolus) и нерадению (culpa), которые в дальнейшем были объединены общим понятием "вина", а конкретно: несоблюдение того поведения, которое требуется правом, которое можно изцожить следующим образом: «Нет вины, если соблюдено все, что требовалось".

В форме небрежности вина (culpa) определямась так: "Вина имеется налицо, если не было предвидено то, что заботмивый мог бы предвидеть" [1].

В настоящее время проблема понятия гражданско-правовой ответственности не решена. Бесспорно, гражданско-правовая ответственность - это санкция за правонарушение, вызывающая для нарушителя возложение отрицательных последствий в виде мишения субъективных гражданских прав, мибо возможение новых гражданско-правовых обязанностей. 
Известно, что наступление гражданско-правовой ответственности напрямую связано с наличием определенных условий (а именно элементов, оснований). По мнению большинства, к объективным элементам относят противоправное действие и его результат (а именно вред, убытки), саму причинную связь между действием и вредом, к субъективным же относят вину правонарушителя [2].

Разумеется, общность элементов состава правонарушения не исключает возможности отдельного анализа каждого из условий. Специфика вины причинителя вреда выражается в том, что этот деликт в некоторых случаях представляет собой основание возникновения гражданско-правовой ответственности вне зависимости от вины. А именно, обязательность следующего условия и представляет собой значимое отличие этого деликта в гражданском законодательстве разАичных стран СНГ.

В своем труде С.Н. Братусь считает, что «основанием ответственности служит нарушение юридического долга; это последнее не может быть допущено иначе как виновно или рискованно. А поскольку психическое отношение к действию и результату заложено и в вине, и в риске, ответственность всегда находит достаточную субъективную мотивацию, каким бы ни было конкретное ее условие" [6].

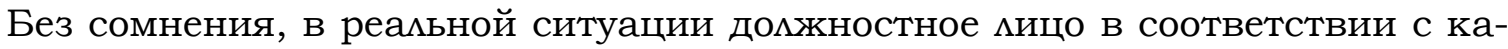
кими-либо обстоятельствами порой и не осознает противоправность совершаемых действий, при этом в соответствии со служебным положением оно, разумеется, сможкет ее осознать. В соответствии с этим А.П. Сергеев подчеркивает взаимосвязь вины и противоправности в анализируемой области, и, следовательно, дока-

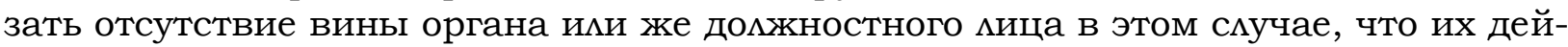
ствия (бездействие) признаны незаконными, достаточно сложно. При этом незаконность акта часто связана с действиями тех миц, которые приняли акт. В связи этими обстоятельствами установленная законом в ст.1064 ГК РФ презумпция вины причинителя вреда практически является неопровержимой.

Таким образом, наблюдается усиление роли ответственности в соответствии с категорией вины и, как следствие этого, закрепление в нормативно-правовых актах новых случаев ответственности к имеющимся, а именно ответственность собственников, а также пользователей за вред, который был причинен принадлежащим вещам дикими животными, разрушающимися строениями и т.п.

\section{СПИСОК ИСПОАЬЗОВАННОЙ АИТЕРАТУРЫ}

1. Бутенко Е.В. Вина в нарушении договорных обязательств: автореф. дисс. ... канд. юрид. наук: 12.00 .03 / Е.В. Бутенко. - Краснодар., 2002. - 23 с.

2. Гражданское право. В 2-х т. Т. 1. Учебник / под ред. Е.А. Суханова. - М. : Волтерс Клувер, 2008. - 736 с.

3. Аукьянчикова Е.Н. Вина как условие привлечения к гражданско-правовой ответственности за нарушения интемлектуальных прав : автореф. дисс. ... канд. юрид. наук: 12.00.03 / Е.Н. Аукьянчикова. - СПб., 2014. - 22 с.

4. Никольский Б.В. Система и текст ХІІ таблиц. Исследования по истории римского права / Б.В. Никольский. - СПб. : тип. А.С. Суворина, 1899. - 294 с.

5. Синенко В.С. Наличие вины как условие ответственности за вред, причиненный актами публичной вмасти / В.С. Синенко // Научные ведомости БелГУ. Сер. Фимософия. Социология. Право. - 2009. - №10 (65). - С. 148-153.

6. Черкун Е.В. Принципы гражданско-правовой ответственности /Е.В. Черкун// Молодой ученый. - 2016. - № 21 (125). - С. 680-682.

7. Чикишева Н.А. Презюмирование вины при применении договорной и деликтной ответственности / Н.А. Чикишева // Вцасть. - 2016. — № 3. - С. 171-178. 


\section{REFERENSES}

1. Butenko E.V. Vina v narushenii dogovornykh obiazatel'stv: avtoref. diss. ... kand. iurid. nauk: 12.00.03 [Fault in violation of contractual obligations: abstract of diss. cand. of law]. Krasnodar, 2002, 23 p.

2. Sukhanov E.A. (ed.) Grazhdanskoe pravo. V 2-kh t. T. 1. Uchebnik [Civil law. In 2 vol. Vol. 1. Textbook]. Moscow, Volters Kluver Publ., 2008, 736 p.

3. Luk'ianchikova E.N. Vina kak uslovie privlecheniia $k$ grazhdansko-pravovoi otvetstvennosti za narusheniia intellektual'nykh prav: avtoref. diss. ... kand. iurid. nauk: 12.00.03 [Fault as condition of attraction to civil responsibility for violations of the intellectual rights: abstract of diss. cand. of law]. Saint Petersburg, 2014, 22 p.

4. Nikol'skii B.V. Sistema i tekst XII tablits. Issledovaniia po istorii rimskogo [System and text of the XII tables. Researches on history of the Roman law]. Saint Petersburg, tip. A.S. Suvorina Publ., 1899, 294 p.

5. Sinenko V.S. Existence of fault as a condition of responsibility for the harm done by acts of the public power. Nauchnye vedomosti BelGU. Ser. Filosofiia. So-tsiologiia. Pravo = Scientific Bulletins of the Belgorod State University. Philosophy. Sociology. Right, 2009, no. 10 (65), pp. 148-153 (in Russian).

6. Cherkun E.V. Principles of civil responsibility. Molodoi uchenyi = The young scientist, 2016, no. 21 (125), pp. 680-682 (in Russian).

7. Chikisheva N.A. Assumption of guilt in the application of contractual and tort liability. Vlast' $=$ The power, 2016, no. 3, pp. 171-178 (in Russian).

\section{ИНФОРМАЦИЯ ОБ АВТОРАХ}

Казакова Евгения Борисовна - кандидат юридических наук, доцент, кафедра частного и публичного права, Пензенский государственный университет, 440026, г. Пенза, ум. Красная 40, Российская Федерация, e-mail: 1-janni@list.ru.

Потолокова Оксана Олеговна - магистрант, Пензенский государственный университет, 440026, г. Пенза, ул. Красная 40, Российская Федерация, e-mail: oksana_223@ inbox.ru.

\section{AUTHORS}

Kazakova Evgeniya Borisovna - Candidate of law, associate professor, department of Private and Public Law, Penza State University, 40 Krasnaya Street, Penza, 440026, the Russian Federation, e-mail: 1-janni@list.ru.

Potolokova Oksana Olegouna - Master student, Penza State University, 40 Krasnaya Street, Penza, 440026, the Russian Federation, e-mail: oksana_223@inbox.ru.

\section{БИБАИОГРАФИЧЕСКОЕ ОПИСАНИЕ СТАТЬИ}

Казакова Е.Б. Гражданско-правовая ответственность / Е.Б. Казакова, О.О. Потолокова // Эмектронный научный журнал "Наука. Общество. Государство». - 2018. - Т. 6, № 2 [Эмектронный ресурс]. — Режим доступа: http://esj.pnzgu.ru.

\section{BIBLIOGRAPHIC DESCRIPTION}

Kazakova E. B., Potolokova O. O. Civil responsibility. Electronic scientific journal "Science. Society. State", 2018, vol. 6, no. 2, available at: http://esj.pnzgu.ru (In Russian). 